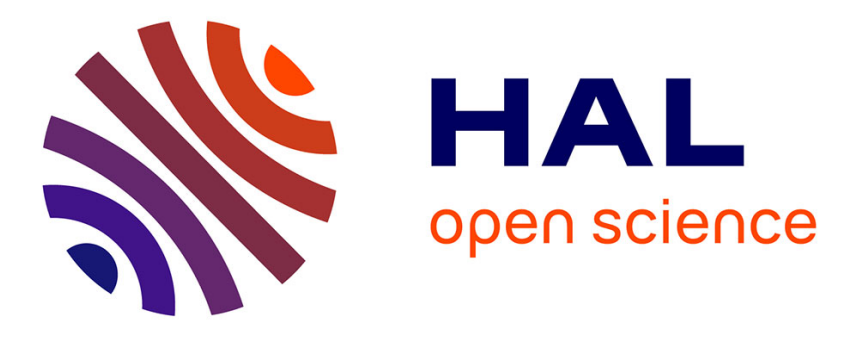

\title{
Self-Assembling Peptide-Polymer Nano-Objects via Polymerization-Induced Self-Assembly
}

Tuyen T. P. Dao, Lubomir Vezenkov, Gilles Subra, Muriel Amblard, Martin

In, Jean-François Le Meins, Florian Aubrit, Mohammad-Amin Moradi,

Vincent Ladmiral, M. Semsarilar

\section{To cite this version:}

Tuyen T. P. Dao, Lubomir Vezenkov, Gilles Subra, Muriel Amblard, Martin In, et al.. Self-Assembling Peptide-Polymer Nano-Objects via Polymerization-Induced Self-Assembly. Macromolecules, 2020, 53 (16), pp.7034-7043. 10.1021/acs.macromol.0c01260 . hal-02915614

\section{HAL Id: hal-02915614 \\ https://hal.science/hal-02915614}

Submitted on 11 Dec 2020

HAL is a multi-disciplinary open access archive for the deposit and dissemination of scientific research documents, whether they are published or not. The documents may come from teaching and research institutions in France or abroad, or from public or private research centers.
L'archive ouverte pluridisciplinaire HAL, est destinée au dépôt et à la diffusion de documents scientifiques de niveau recherche, publiés ou non, émanant des établissements d'enseignement et de recherche français ou étrangers, des laboratoires publics ou privés. 


\section{Self-assembling Peptide - Polymer Nano-Objects via Polymerization-Induced Self-Assembly}

T. P. Tuyen Dao ${ }^{a, b, c}$, Lubomir Vezenkov ${ }^{c}$, Gilles Subra ${ }^{c}$, Muriel Amblard $^{c}$, Martin In ${ }^{d}$, Jean-François Le Meins ${ }^{e}$, Florian Aubrit ${ }^{e}$, Mohammad-Amin Moradif, Vincent Ladmiral ${ }^{b}$, Mona Semsarilar ${ }^{a *}$

a: Institut Européen des Membranes, IEM, Univ Montpellier, CNRS, ENSCM, Montpellier, France.

b: Institut Charles Gerhardt Montpellier, ICGM, Univ Montpellier, CNRS, ENSCM, Montpellier, France.

c: Institut des Biomolécules Max Mousseron, IBMM, Univ Montpellier, CNRS, ENSCM, Montpellier, France.

d: Laboratoire Charles Coulomb, L2C, Univ Montpellier, CNRS, Montpellier, France.

e: Laboratoire de Chimie des Polymères Organiques, LCPO UMR 5629, Université Bordeaux, CNRS, Pessac, France.

f: Institute for Complex Molecular Systems, Eindhoven University of Technology, Eindhoven, The Netherlands.

KEYWORDS: PISA, Polymerization-induced self-assembly, Self-assembling peptide, peptide-polymer nano-objects 
ABSTRACT: Self-assembling peptides (SAP) have been extensively studied for their ability to form nanoscale ordered structures driven by non-covalent molecular interactions. Meanwhile, polymerization-induced self-assembly (PISA) has been exploited as a facile and efficient way to produce various amphiphilic block copolymer nano-objects, whose self-assembly was governed predominantly by the interactions of the different blocks with the polymerization medium. In this work, we combined PISA with SAP to prepare novel peptide-polymer hybrid nano-objects, thus harnessing the advantages of PISA and the self-assembling driving force of SAP. A tripeptide methacrylamide derivative (MAm-GlyPhe-Phe- $\mathrm{NH}_{2}$, denoted MAm-GFF where MAm means methacrylamide) was copolymerized with glycerol monomethacrylate (GMA) to produce $\left.\mathrm{P}\left(\mathrm{GMA}_{65} \text {-stat-(MAm-GFF) }\right)_{7}\right)$ macro-chain transfer agent (macro-CTA) by Reversible addition-fragmentation chain transfer (RAFT) polymerization in DMF. This peptide-based macro-CTA was then successfully chain-extended with poly(2-hydroxypropyl methacrylate) (PHPMA) by aqueous dispersion PISA, forming $\mathrm{P}\left(\mathrm{GMA}_{65}\right.$-stat-(MAm-GFF) $\left.{ }_{7}\right)-b$-PHPMA 28 self-assembled objects. Fibrous structures were observed by TEM and Cryo-TEM in agreement with DDLS, SLS and SAXS experiments that also revealed long anisotropic morphologies. Such structures have not been reported previously for PISA-prepared nano-objects. This confirms the decisive influence of the GFF SAP on the self-assembly. In addition, annealing the PISA suspension at different temperatures led to a significant size decrease of the self-assembled objects and to a morphological transition caused by the thermo-sensitivity of both the core-forming PHPMA block and the stabilizing P(GMAstat-(MAm-GFF)) block.

\section{INTRODUCTION}

Polymerization-induced self-assembly (PISA) is a way to produce block copolymer nano-objects, in which the self-assembly is induced during the formation of the block copolymer. In PISA, a solventsoluble first polymer is chain extended with a second polymer generally using a reversible deactivation radical polymerization (RDRP) technique. ${ }^{1-7}$ The polymerization solvent is chosen to be selective of the 
first block so that the growing second block becomes insoluble as the polymerization progresses, thus inducing the self-assembly in-situ. First reported in $2002,{ }^{8}$ although not called PISA then, this simple synthetic method gained momentum in the last few years ${ }^{9}$ for its ability to produce well-defined polymer nano-objects at high concentration and with high reproducibility. PISA has been demonstrated to work well under dispersion ${ }^{10-14}$ or emulsion polymerization ${ }^{15-18}$ both in polar solvents (water, alcohols, ... $)^{19-25}$ or non-polar solvents (alkanes, toluene, ...). ${ }^{26-29}$ Less conventional solvents such as ionic liquids ${ }^{30}$ or supercritical $\mathrm{CO}_{2}{ }^{31-33}$ were also successfully used for PISA protocols. Although PISA can result in a large variety of morphologies, spheres, worms or vesicles with controlled size and functionality ${ }^{2,11}$, 34-38 are the most common PISA morphologies.

Hybrid peptide-polymers are an important class of materials combining interesting characteristics of their peptide and polymer components. Ideally, these structures should possess the biocompatibility and biofunctionality of peptides as well as the robustness and functional diversity conferred by the polymer chains. They can be prepared by various approaches (i.e. post polymerization grafting, grafting-from or grafting-through) $)^{39-43}$ resulting in a wide variety of morphologies, functionalities and potential applications. Recently, our group reported the first polypeptide-polymer nanoparticles synthesized via PISA. ${ }^{44}$ These hybrid particles were composed of a hydrophilic trilysine-containing shell and a PHPMA hydrophobic core. The cationic oligolysine was shown to confer antibacterial properties to the self-assembled structures.

Nano-objects based on peptides self-assembly have also gained attraction, especially for tissue engineering and drug delivery applications ${ }^{45}$ due to their biocompatibility, and ease of synthesis and modification to yield bioactivity. ${ }^{46,47}$ Self-assembling peptides (SAP) were used in a bottom-up approach to form a variety of stable supramolecular nanostructures, such as fibers, rods, tubes, nano-vesicles or spheres. ${ }^{45}$ Their self-assembly is driven by non-covalent interactions such as hydrogen bonding, $\pi-\pi$ stacking, van 
der Waals forces or electrostatic interactions. ${ }^{48}$ Thus, their organization could be triggered and finely regulated by different parameters such as ionic strength, $\mathrm{pH}$ and temperature.

In this context, exploring the combination of PISA and SAP peptide in block copolymer self-assembly appears very interesting. Such systems could be significantly influenced not only by physicochemical parameters such as the solubility and the hydrophobic/hydrophilic balance between the two components of the block copolymers, but also by the specific self-recognition properties of the peptide moieties. Consequently, a methacrylamide (MAm) functionalized tripeptide monomer (MAm-Gly-Phe-Phe- $\mathrm{NH}_{2}$, denoted MAm-GFF) was synthesized. The GFF motif was chosen for the simple diphenylalanine sequence which has been the most extensively studied SAP reported so far. ${ }^{49,50}$ Depending on conditions, this dipeptide and its numerous derivatives can self-assemble into nanotubes, ${ }^{51}$ nanowires, ${ }^{52}$ nanovesicles ${ }^{53}$ or fibers. ${ }^{54}$ Aromatic interactions and hydrogen bonds between diphenylalanine moieties are considered critical for the formation of these distinct nanostructures. ${ }^{55-57}$ A glycine residue was used as a spacer between the self-recognition element and the polymerizing unit. MAm-GFF was statistically copolymerized with a hydrophilic monomer (glycerol monomethacrylate, GMA) by Reversible additionfragmentation chain-transfer (RAFT) polymerization to form the target SAP-containing macromolecular chain transfer agent (macro-CTA). This (MAm-GFF)-containing macro-CTA was chain-extended with poly (2-hydroxypropyl methacrylate) (PHPMA) under aqueous dispersion PISA. GMA and HPMA were chosen since they are highly biocompatible and because the PGMA- $b$-PHPMA PISA system has been thoroughly studied and reported, ${ }^{12,34,58-62}$ thus it constitutes a very useful benchmark to understand the influence of SAP on the final morphologies. The synthetic approach in this work is illustrated in scheme 1. Scattering and imaging techniques were used to characterize the resulting nano-objects. Particularly, the change in shape and size of the objects was examined via cooling-heating cycles.

Scheme 1. Syntheses of the P(GMA-stat-(MAm-GFF)) macro-CTA using RAFT and of P(GMA-stat(MAm-GFF))-b-PHPMA block copolymers under PISA conditions. 


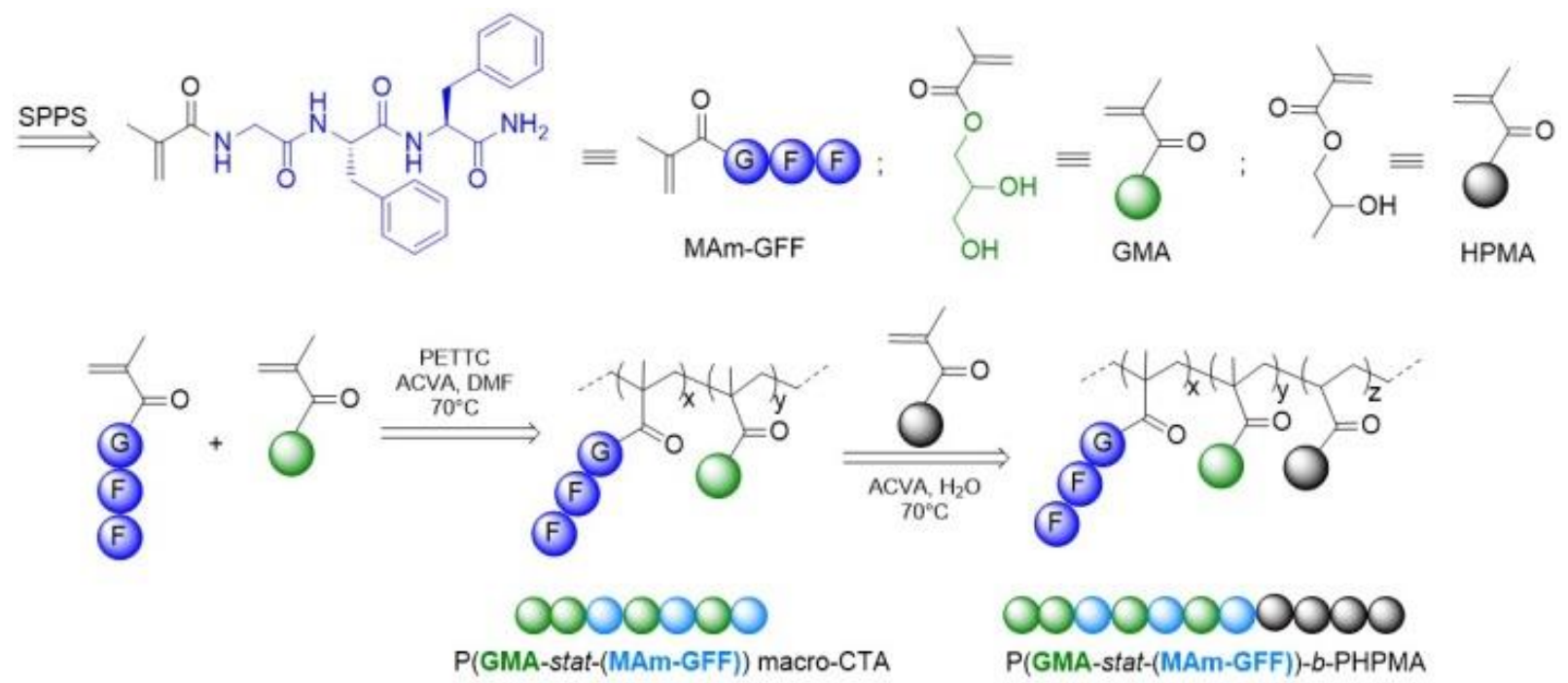

\section{MATERIALS AND METHODS}

\section{Materials}

Fmoc-amino acid derivatives (Fmoc-Phe-OH, Fmoc-Gly-OH), HATU (1[Bis(dimethylamino)methylene]-1H-1,2,3-triazolo[4,5-b]pyridinium 3-oxide hexafluorophosphate) and Polystyrene Fmoc Rink Amide resin (100-200 mesh) with a loading of $0.94 \mathrm{mmol} / \mathrm{g}$ were purchased from Iris Biotech GmbH. Methacrylic acid, Piperidine, N,N-Diisopropylethylamine (DIEA), Trifluoroacetic acid (TFA), 2-hydroxypropyl methacrylate (HPMA), Glycerol monomethacrylate (GMA), 4,4'azobis(4-cyanopentanoic acid) (ACVA) and all organic solvents (Dichloromethane (DCM), Acetonitrile (ACN), Dimethylformamide (DMF), Ethanol) were purchased from Sigma-Aldrich. The NMR deuterated solvents $\left(\mathrm{D}_{2} \mathrm{O}\right.$, DMSO-d6, DMF-d7) were purchased from Eurisotop. The RAFT agent 4-cyano-4-(2phenylethanesulfanylthiocarbonyl)-sulfanylpentanoic acid (PETTC) was prepared as previously described. ${ }^{10}$ All reagents were used as received.

\section{Synthesis of methacrylamide-functionalized peptide monomer (MAm-GFF)}

The GFF peptide sequence was prepared using standard Fmoc Solid Phase Peptide Synthesis (SPPS) method $^{63}$ with a CEM Liberty ${ }^{\circledR}$ microwave automated peptide synthesizer on a 4 mmol scale $(4.26 \mathrm{~g}$ resin). DMF was used as solvent, HATU was used as the activating agent in the presence of DIEA and 
Piperidine/DMF 20/80 v/v mixture was used as the Fmoc-deprotecting solution. For each amino acid coupling, $35 \mathrm{~mL}$ of Fmoc-protected amino acid solution at concentration of $0.4 \mathrm{M}$ in DMF (14 mmol, 3.5 equiv), $14 \mathrm{~mL}$ of HATU at concentration $1 \mathrm{M}$ in DMF (14 mmol, 3.5 equiv) and $2.8 \mathrm{~mL}$ of DIEA (16 mmol, 4 equiv) was loaded to the microwave reactor. After each coupling, the Fmoc-protecting group was removed with mixture of Piperidine/DMF 20/80 v/v and the resin was washed prior to subsequent coupling. Once target peptide sequence was obtained, the resin was transferred into a reaction vessel and reacted with $35 \mathrm{~mL}$ of a mixture containing $1.2 \mathrm{~g}$ of methacrylic acid (3.5 equiv), $5.32 \mathrm{~g}$ HATU (3.5 equiv), $2.76 \mathrm{~mL}$ DIEA (4 equiv) in DMF for $1 \mathrm{~h}$ at room temperature. The resin was then washed with DMF (20 mL x 3), then, with DCM (20 mL x 3) and dried by nitrogen purging. The Nterminally methacrylated peptide was cleaved from the resin with a TFA/DCM (1/1) mixture for $2 \mathrm{~h}$ at room temperature. The resin was then filtered and concentrated under reduced pressure. The peptide was recovered by precipitation in cold diethyl ether, then taken up in ACN/water 50/50 v/v mixture and freeze-dried. No further purification step was needed. MAm-GFF was obtained as a white solid (1.45 g, $83 \%$ yield) and analysed by LC-MS and ${ }^{1} \mathrm{H}$ NMR (Figure S1, S2 Supporting Information). ${ }^{1} \mathrm{H}$ NMR in DMSO $\delta(\mathrm{ppm}): 1.85$ (s, 3H, - $\left.\mathrm{CH}_{3}\right) ; 2.72\left(\mathrm{dd}, 2 \mathrm{H},-\mathrm{NH}-\mathrm{CH}_{2}-\mathrm{CO}\right) ; 2.82-3.08$ (m, 4H, -CH-CH2-Ph); 4.41 (m, 2H, -NH-CHCO-CH2- ( $_{2} ; 5.38$ (s, 1H, vinyl); 5.71 (s, 1H, vinyl); 7.10-7.28 (m, 10H, phenyl); 8.08$8.20(\mathrm{~m}, 3 \mathrm{H},-\mathrm{NH}-)$.

Note: All peptides used were enantiomerically pure. They were prepared from a single (L) isomer of each amino acid, with state of the art and well established procedures of solid phase peptide synthesis. In this strategy, the peptides were synthesized stepwise from the $\mathrm{C}$ to $\mathrm{N}$ terminus using urethaneprotected amino acids that avoid any risk of epimerization.

\section{RAFT copolymerization of GMA and MAm-GFF}

The general procedure for the synthesis of copolymer P(GMA-stat-(MAm-GFF)) macro-CTA is as follows: a round bottom flask equipped with a stirrer bar was charged with GMA (1 g, 6.242 mmol), 
MAm-GFF (378 mg, $0.865 \mathrm{mmol})$, PETTC RAFT agent (32.6 mg, $0.096 \mathrm{mmol})$, ACVA initiator (2.69 $\mathrm{mg}, 0.0096 \mathrm{mmol}$ ) and DMF. The flask was subsequently sealed with a rubber septum, the reaction mixture was degassed by bubbling nitrogen for $30 \mathrm{~min}$ and the flask was immersed in a preheated oil bath at $70^{\circ} \mathrm{C}$. The reaction was conducted under stirring for $24 \mathrm{~h}$. Then the copolymerization was quenched by opening the reaction to air and the conversion was determined by ${ }^{1} \mathrm{H}$ NMR. GMA conversion was determined from the proton integral ratios of its residual vinyl signals at $5.65 \mathrm{ppm}(1 \mathrm{H})$ or $6.15 \mathrm{ppm}(1 \mathrm{H})$ to the signals at 3.5-4.1 $(5 \mathrm{H})$ whereas the MAm-GFF conversion was obtained from the comparison of its residual vinyl signals at $5.42(1 \mathrm{H})$ or $5.85(1 \mathrm{H})$ to the phenyl group at 7.2-7.4 $(10 \mathrm{H})$. The reaction solution was diluted in DMF and precipitated in cold THF. The yellow precipitate was then re-dispersed in water and freeze-dried. DMF GPC analysis of final product indicated $\mathrm{M}_{\mathrm{n}}=18,290 \mathrm{~g} / \mathrm{mol}$ with $\mathrm{M}_{\mathrm{w}} / \mathrm{M}_{\mathrm{n}}$ $=1.32$ (Figure 6) while ${ }^{1} \mathrm{H}$ NMR gave the mean DP of PGMA and PMAm-GFF are 65 and 7 respectively (Figure S3 Supporting Information).

For the copolymerization kinetic study, DMF-d7 was used as solvent. The reaction mixture was deoxygenated in a Schlenk flask then transferred into an NMR tube under nitrogen atmosphere. The ${ }^{1} \mathrm{H}$ NMR spectra were recorded at time $\mathrm{t}=0$ (just after putting the sample at $70^{\circ} \mathrm{C}$ in the $\mathrm{NMR}$ spectrometer), at 30 min intervals during the first three hours and every hour for the remaining time until the reaction was finished.

\section{PISA via RAFT aqueous dispersion polymerization}

PISA protocol was performed via RAFT aqueous dispersion polymerization of HPMA with P(GMA65stat-(MAm-GFF) $\left.{ }_{7}\right)$ macro-CTA as described below. The purified $\mathrm{P}\left(\mathrm{GMA}_{65}\right.$-stat-(MAm-GFF) $\left.{ }_{7}\right)$ macroCTA (200 mg, $0.0145 \mathrm{mmol})$, HPMA (58.5 mg, $0.406 \mathrm{mmol})$ and ACVA initiator (1.0 mg, 0.0036 mmol) were weighed into a $10-\mathrm{mL}$ glass vial containing a stirrer bar. $2.34 \mathrm{~mL}$ MilliQ water was then added to get a reaction solution at $10 \% \mathrm{w} / \mathrm{w}$. The vial was sealed, degassed for 30 minutes and put into an oil bath previously set at $70^{\circ} \mathrm{C}$ using a stirring hotplate. After $24 \mathrm{~h}$, reaction was opened to the air, 
cooled down to ambient temperature and aliquots were taken to run ${ }^{1} \mathrm{H}$ NMR, GPC, TEM, Cryo-TEM, DDLS, SLS and SAXS.

\section{Liquid chromatography - mass spectrometry (LC-MS)}

LC-MS analyses were performed on Waters Alliance 2695 HPLC system, coupled to a Water Micromass ZQ spectrometer (electrospray ionization mode, ESI+). The peptide monomer MAm-GFF was dissolved in a small amount of DMF and diluted with acetonitrile/water $(50 / 50 \mathrm{v} / \mathrm{v})$ mixture containing $0.1 \%$ TFA. UV detection was performed at $214 \mathrm{~nm}$.

\section{Proton nuclear magnetic resonance spectroscopy $\left({ }^{1} \mathrm{H}\right.$ NMR)}

${ }^{1} \mathrm{H}$ NMR spectra were recorded on a $300 \mathrm{MHz}$ Bruker Avance-300 spectrometer, processed and analyzed with MestReNova 9.0 software.

\section{Gel Permeation Chromatography (GPC)}

Polymer molar mass distributions were analysed using a GPC Varian 390-LC system fitted with 2 PL1113-6300 ResiPore $300 \times 7.5$ columns thermostated at $70^{\circ} \mathrm{C}$ and connected to a 390LC PL03900601 refractive index detector $(\mathrm{RI})$. The mobile phase was DMF containing $0.1 \% \mathrm{w} / \mathrm{w} \mathrm{LiBr}$ at a flow rate of $1 \mathrm{~mL} \mathrm{~min}^{-1}$. The calibration was achieved with near-monodisperse poly(methyl methacrylate) (PMMA) standards ranging from 550 to $1568000 \mathrm{~g} \mathrm{~mol}^{-1}$ (EasiVial-Agilent).

\section{Circular Dichroism (CD)}

The CD spectra were recorded on a JASCO J-815 Spectropolarimeter. MAm-GFF was dissolved in ethanol $(0.02$ and $0.04 \% \mathrm{w} / \mathrm{w})$ and loaded into a $1 \mathrm{~mm}$ quartz cuvette. Spectra were obtained from 190-260 nm with $0.1 \mathrm{~nm}$ step, $1 \mathrm{~nm}$ bandwidth and $100 \mathrm{~nm} / \mathrm{min}$ for scanning speed.

\section{X-Ray Diffraction (XRD)}

XRD was employed on the Philips Xpert Pro Diffractometer with $\mathrm{Cu} \mathrm{Ka}$ radiation $(\mathrm{k}=1.54 \AA)$. The sample was scanned from $5^{\circ}$ to $50^{\circ}$ with steps of $0.033^{\circ}$. 


\section{Light scattering (LS)}

The hydrodynamic radii were analyzed by dynamic light scattering at $90^{\circ}$ using an Anton Paar Litesizer TM 500. Samples were prepared at $0.1 \%$ w/w by diluting the PISA suspension 100 -fold with MilliQ water. The measurements were performed at $25^{\circ} \mathrm{C}$ or for varied temperature from $20^{\circ} \mathrm{C}$ to $70^{\circ} \mathrm{C}$ with $10^{\circ} \mathrm{C}$ intervals, 30 minutes of equilibration was set at the target temperature prior each measurement.

Depolarized Dynamic Light Scattering (DDLS) measurements were also performed, thanks to the prototype of the Thetis multiangle DDLS setup commercialized by Cordouan Technologies (Pessac, France) consisting of two detector cells located at various angles respectively to the incident laser beam. Each of the cells detected either the polarized or depolarized transmitted beam, through the splitting of this beam by a polarizing cube. The data for characterizing the anisotropy of the particles were then treated following the theoretical model developed with Broersma's equations. ${ }^{64}$

\section{Small angle X-Ray scattering (SAXS)}

The SAXS experiments were performed under transmission configuration using an in-house setup at the Laboratory Charles Coulomb (Montpellier, France). A high brightness, low power X-ray tube, coupled with an aspheric multilayer optic (GeniX ${ }^{3 \mathrm{D}}$ from Xenocs) delivers an ultralow divergent beam $(0.5$ mrad, $\lambda=0.15418 \mathrm{~nm}$ ). Scatterless slits were used to give a clean $0.6 \mathrm{~mm}$ beam diameter with a flux of 35 Mphotons per second) on the sample. Samples were contained in lineman tubes of $1 \mathrm{~mm}$ external diameter and $0.1 \mathrm{~mm}$ thickness. We worked in a transmission configuration and the scattered intensity was measured using a 2D "Pilatus" 300K pixel detector by Dectris $(490 * 600$ pixels) with pixel size of $172 * 172 \mu \mathrm{m}^{2}$, at a distance of $1.9 \mathrm{~m}$ from the sample. Sample SAXS intensity is the average of six scans obtained after an exposition time of $30 \mathrm{~min} / \mathrm{scan}$ that corresponds to 3 hours of data acquisition time. The 2D signal on the plate was translated into I(q) signal using FIT2D. All intensities were corrected for transmission, empty cell and solvent contribution. The measurements were run directly from the concentrated PISA suspension at $10 \% \mathrm{w} / \mathrm{w}$. 


\section{Transmission Electron Microscopy (TEM)}

TEM images were acquired using either a JEOL 1200 EXII - $120 \mathrm{kV}$ or a JEOL $1400 \mathrm{P}+-120 \mathrm{kV} .10$ $\mu \mathrm{L}$ of diluted PISA suspension $(0.1 \% \mathrm{w} / \mathrm{w})$ was deposited onto the grid for $60 \mathrm{~s}$ and then blotted with filter paper to remove excess solution. Afterward, the sample-loaded grid was stained with $7 \mu \mathrm{L}$ of $1 \%$ ammonium molybdate solution for $20 \mathrm{~s}$ before this solution wasremoved with filter paper. The grid was allowed to dry for 5 minutes under the fumehood. For the study at $70^{\circ} \mathrm{C}$ or $5^{\circ} \mathrm{C}, 10 \% \mathrm{w} / \mathrm{w}$ PISA suspension was incubated at the desired temperature during $1 \mathrm{~h}$ and diluted to $0.1 \% \mathrm{w} / \mathrm{w}$ with MilliQ water at the same temperature. Samples were quickly loaded onto the grid using the protocol described above, but in these cases, the grids were prepared in an oven chamber set at $70^{\circ} \mathrm{C}$ or in a fridge.

\section{Cryogenic Transmission Electron Microscopy (Cryo-TEM)}

Cryo-TEM analysis was performed using a CryoTitan (Fisher Scientific Corp) operating at $300 \mathrm{kV}$ and equipped with a field emission gun (FEG). The TEM grids were glow discharged with a Cressington 208 carbon coater. Vitrified samples were prepared from a $3 \mu \mathrm{L}$ droplet of solution pipetted on the grid inside the VitrobotTM at the highest relative humidity and room temperature. The samples were blotted to remove the excess solution and plunged into liquid ethane by using the automated vitrification robot, VitrobotTM (Mark III, FEI Corp) to achieve an electron transparent sample in amorphous ice around a lacey carbon grid.

\section{RESULTS AND DISCUSSION}

\section{Methacrylamide-functionalized peptide monomer MAm-GFF}

Standard Fmoc solid phase peptide synthesis were successfully applied to prepare the methacrylamidefunctionalized peptide monomer MAm-GFF with a good yield (83\%) and high purity, as proved by LCMS and ${ }^{1} \mathrm{H}$ NMR spectrum shown in Figure S1 and S2 Supporting information. MAm-GFF is rather hydrophobic, insoluble in water but could be dispersed in ethanol. DLS analysis the dispersion of MAm-GFF in ethanol at $0.1 \% \mathrm{w} / \mathrm{w}$ indicated poor solubility shown by the presence of micrometric 
self-assembled objects. Representative TEM images of the structures obtained from this dispersion are shown in Figure 1. These images show bundles of rather monodisperse fibers, $1.50 \pm 0.14 \mu \mathrm{m}$ long and $0.35 \pm 0.03 \mu \mathrm{m}$ wide, with dozen fibers per bundle, each about $40 \mathrm{~nm}$ in width. X-Ray powder diffraction proved the crystallinity of these fibers (Figure 2). The sharp distinct peaks of MAm-GFF are consistent with those seen in the X-ray diffractograms of L-phenylalanine-based molecules. ${ }^{55,}{ }^{65-68}$ Furthermore, CD spectroscopy was also employed to extract more information about the self-assembly of MAm-GFF in ethanol. The clear positive signal observed at $222 \mathrm{~nm}$, also observed in previous studies of L-phenylalanine derivatives, was assigned to $\pi-\pi^{*}$ transitions resulting from aromatic stacking of the phenylalanine residues. ${ }^{69}$ Hence, the self-organization into supramolecular structures of MAm-GFF was attributed to aromatic stacking interactions between FF moieties. In addition, recent experimental and theoretical studies suggested that the self-assembled nanostructures formed from FF-containing molecules are also stabilized via $\mathrm{H}$ bonding (FF-FF, FF-solvent) and other weak forces such as hydrophobic, electrostatic and Van der Waals interactions between non-polar moieties. ${ }^{56}$ In the case of MAm-GFF, Hbonds between the amide groups most likely contribute to the self-assembly.
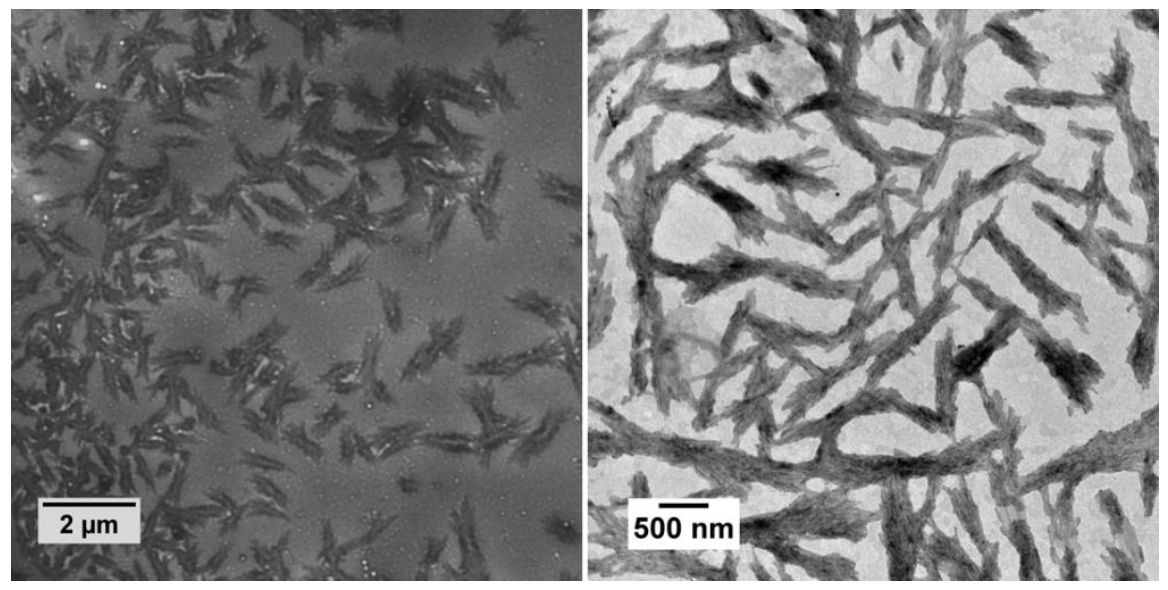

Figure 1. Representative TEM images of structures obtained from MAm-GFF solution in ethanol at 0.1

$$
\% \mathrm{w} / \mathrm{W} \text {. }
$$



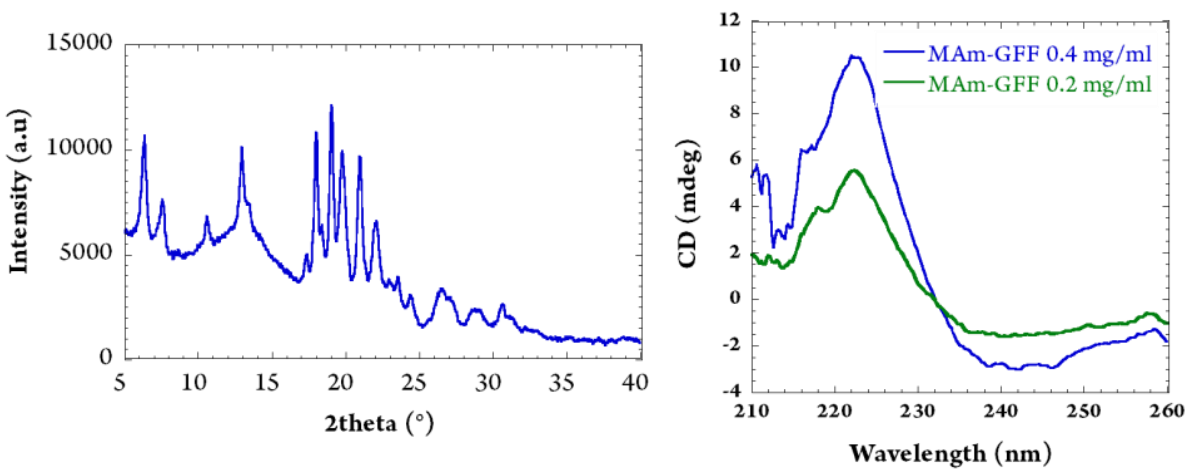

Figure 2. X-ray diffractogram of MAm-GFF powder (left), and CD spectra of MAm-GFF in ethanol at 0.2 and $0.4 \mathrm{mg} / \mathrm{mL}$ (right).

\section{P(GMA-stat-(MAm-GFF)) macro-CTA}

Due to the insolubility of PMAm-GFF in water, PISA protocols in water using such macromolecular chain transfer agent (mCTA) cannot be easily performed. Instead, a more hydrophilic macro-CTAs prepared by copolymerization in DMF of MAm-GFF and glycerol monomethacrylate (GMA, a common monomer in PISA-formulations) was used. ${ }^{12,20,34,70-73}$ The monitoring of the conversions of each monomer during the copolymerization by in-situ ${ }^{1} \mathrm{H}$ NMR kinetic study (Figure 3) shows that MAm-GFF was consumed slightly slower than GMA. GMA was almost completely polymerized after 5h but MAmGFF conversion only reached $80 \%$. However, both monomers started and stopped copolymerizing at the same time (after about 240 mins). This suggests the formation of a statistical P(GMA-stat-(MAm-GFF)) copolymer. The slightly slower rate of polymerization observed for MAm-GFF could be caused by the steric hindrance of the GFF moiety. Using these reaction conditions, a well-defined $\mathrm{P}\left(\mathrm{GMA}_{65}-\right.$ stat$\left.(\mathrm{MAm}-\mathrm{GFF})_{7}\right)$ copolymer was prepared $\left(\mathrm{M}_{\mathrm{n}}=18,290, Ð=1.32\right)$. This copolymer was easily dispersed in water at $10 \% \mathrm{w} / \mathrm{w}$. 
DLS and TEM analyses were performed to investigate the assembled-state of this MAm-GFFcontaining macro-CTA. The copolymer was dispersed in MilliQ water at a concentration of $0.1 \% \mathrm{w} / \mathrm{w}$ and stirred gently overnight. TEM images of this dispersion, shown in Figure 4, revealed the formation of bundles of fibers or ribbons with diameter between 60 and $500 \mathrm{~nm}$. The bundles were about $10 \mu \mathrm{m}$ and contained a large number of ribbons. Compared to the bundles formed by MAm-GFF (Figure 1), these copolymer bundles were less aligned and thus formed hyperboloids.

$(*)$

$(* *)$

$(*)$

$\left({ }^{* *}\right) \quad 300 \mathrm{~min}$

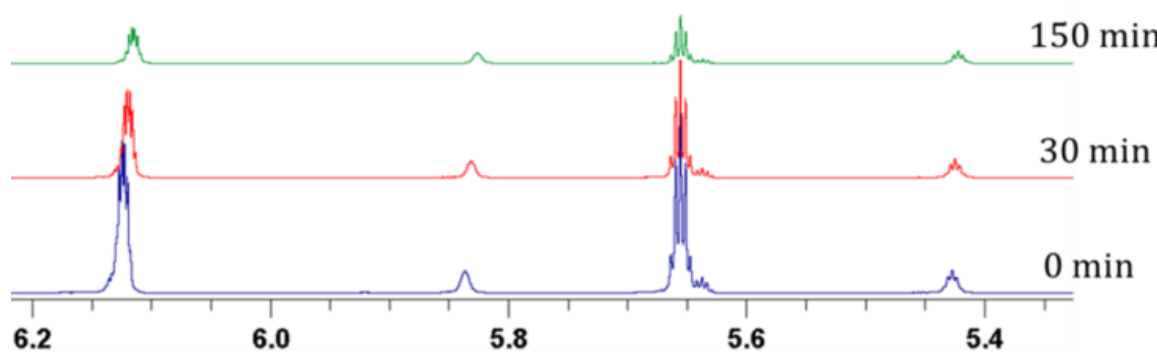

$\left({ }^{* *}\right)$ : vinyl signal of GMA

$\left({ }^{* *}\right)$ : vinyl signal of MAm-GFF

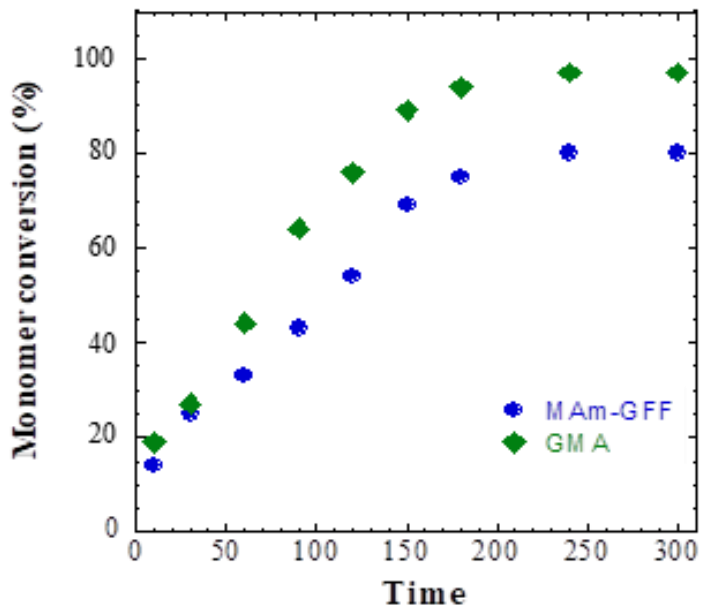

Figure 3. Evolution of monomer conversion with polymerization time for the RAFT statistical copolymerization of GMA and MAm-GFF as studied by ${ }^{1} \mathrm{H}$ NMR spectroscopy. Data points for the GMA and 
MAm-GFF are denoted by green lozenges and blue spheres respectively. Reaction conditions: [GMA $]_{0}$ : $[\mathrm{MAm}-\mathrm{GFF}]_{0}:[\mathrm{PETTC}]_{0}:[\mathrm{ACVA}]_{0}=65: 9: 1: 0.1$ in DMF-d7 at $70^{\circ} \mathrm{C}$.

The influence of temperature on the self-assembly behavior of the $\left.\mathrm{P}\left(\mathrm{GMA}_{65} \text {-stat-(MAm-GFF }\right)_{7}\right)$ macroCTA was investigated by DLS and TEM over the $30^{\circ} \mathrm{C}-70^{\circ} \mathrm{C}$ range. Heating is indeed known to disrupt supramolecular interactions such as H-bonding or pi-stacking. The DLS analyses showed that the size of the self-assembled structures gradually decreased with increasing temperature (Figure 5). At $30^{\circ} \mathrm{C}$, a trimodal size distribution was detected with broad peaks observed at $20 \mathrm{~nm}, 200 \mathrm{~nm}$ and $5 \mu \mathrm{m}$. At 40 ${ }^{\circ} \mathrm{C}$, the smaller peak disappeared and the other distribution narrowed. From $50^{\circ} \mathrm{C}$ upwards, and at $70^{\circ} \mathrm{C}$, only one narrow peak centered at approximately $250 \mathrm{~nm}$ was observed. TEM samples prepared at $70^{\circ} \mathrm{C}$ also confirmed the change in size of the structures, compared to the images taken for samples prepared at ambient temperature (about $30^{\circ} \mathrm{C}$ ). At $70^{\circ} \mathrm{C}$, the copolymer still self-assembles into fibrous bundles but of smaller length and diameter. This TEM image also show fuzzier interfaces for the morphologies compared to those imaged at $30^{\circ} \mathrm{C}$, which is consistent with a higher degree of solvation.
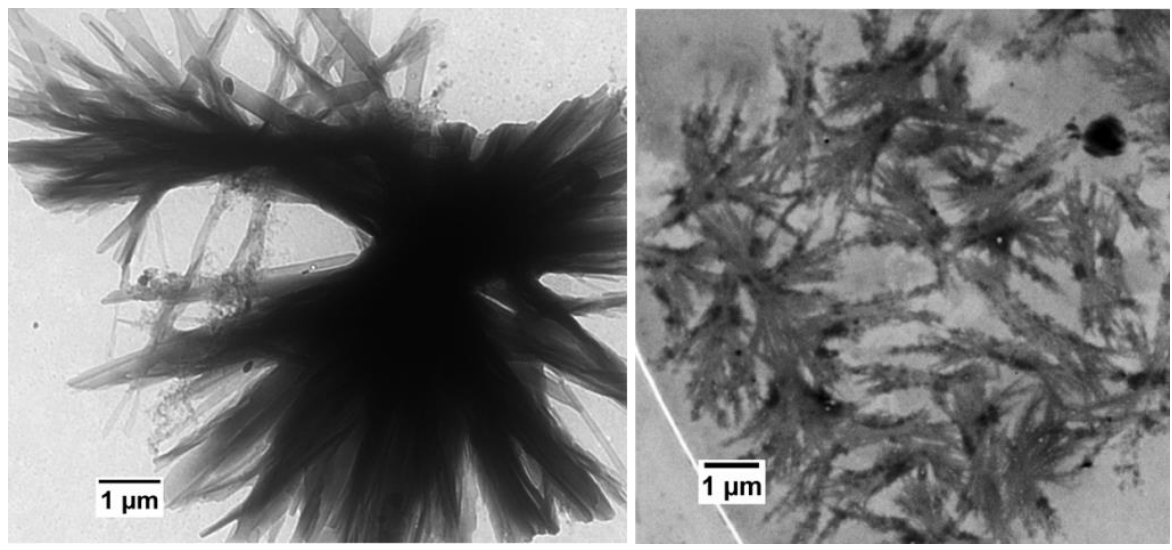

Figure 4. Representative TEM images of $\left.\mathrm{P}\left(\mathrm{GMA}_{65} \text {-stat-(MAm-GFF }\right)_{7}\right)$ macro-CTA in MilliQ water at $0.1 \% \mathrm{w} / \mathrm{w}$ at ambient temperature (about $30^{\circ} \mathrm{C}$ ) (left) and at $70^{\circ} \mathrm{C}$ (right). 


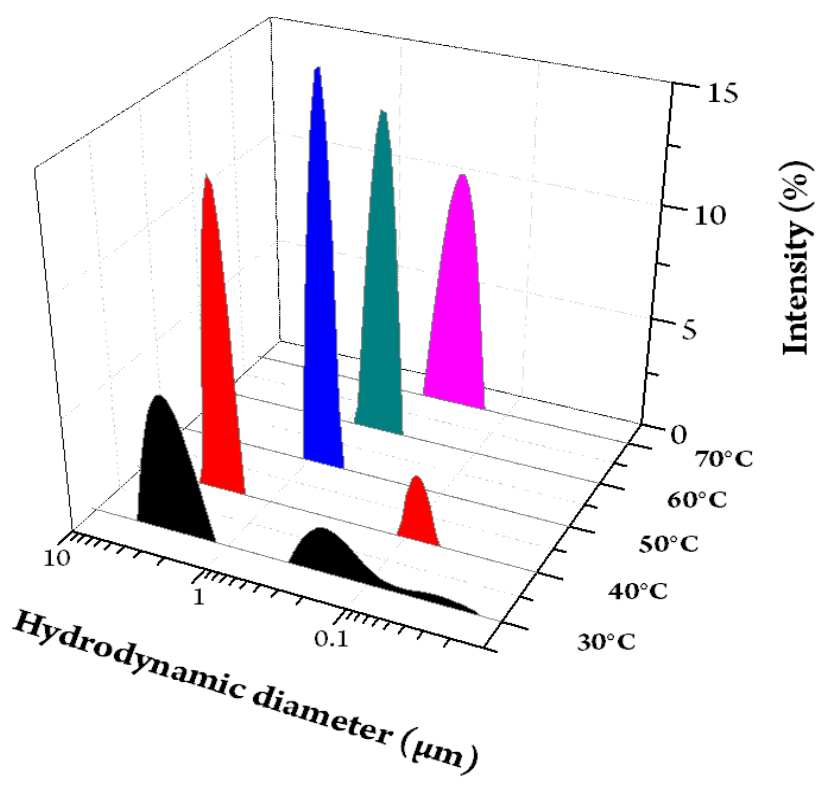

Figure 5. Intensity-average hydrodynamic diameter distribution of $\mathrm{P}\left(\mathrm{GMA}_{65} \text {-stat-(MAm-GFF }{ }_{7}\right)_{\text {mac- }}$ ro-CTA in MilliQ water at $0.1 \% \mathrm{w} / \mathrm{w}$ over the $30^{\circ}-70^{\circ} \mathrm{C}$ range.

To examine the possible influence of HPMA on the structure of the P(GMA ${ }_{65}$-stat-(MAm-GFF $\left.)_{7}\right)$ macroCTA, a mixture of macro-CTA with HPMA in water at $10 \% \mathrm{w} / \mathrm{w}$ was prepared and heated overnight at $70{ }^{\circ} \mathrm{C}$. This mixture was then diluted to $0.1 \% \mathrm{w} / \mathrm{w}$ and analysed by DLS and TEM. As shown in Figure S4 the TEM images do not show any specific change as compared to the images shown in Figure 4. In addition, the object size obtained from DLS at $70{ }^{\circ} \mathrm{C}$ in presence of HPMA is comparable to the data shown in Figure 5, suggesting that HPMA does not act as co-solvent for the macro-CTA, as the observed morphology and size were unaffected.

\section{P(GMA-stat-(MAm-GFF))-b-PHPMA nano-objects via PISA}

The RAFT aqueous dispersion polymerization of HPMA using the P(GMA 65 -stat-(MAm-GFF $\left.)_{7}\right)$ macroCTA was conducted at $10 \% \mathrm{w} / \mathrm{w}$ and yielded well-defined $\mathrm{P}\left(\mathrm{GMA}_{65}-\right.$ stat-MAm-GFF $)-b$-PHPMA 28 
diblock copolymer self-assembled nanostructures. As in a typical aqueous dispersion polymerization, the reaction mixture became increasingly cloudy, signaling the formation of aggregates. $100 \%$ conversion of the HPMA was obtained after $24 \mathrm{~h}$ as judged by ${ }^{1} \mathrm{H}$ NMR spectroscopy. Formation of the diblock copolymer via chain extension of the macro-CTA with PHPMA was confirmed by SEC as shown in Figure $6(\mathrm{D}=1.32)$. The resulting diblock copolymer dispersion was stable throughout the polymerization. No sedimentation or creaming was observed and the dispersion remained colloidally stable for six months when stored at $4{ }^{\circ} \mathrm{C}$. To

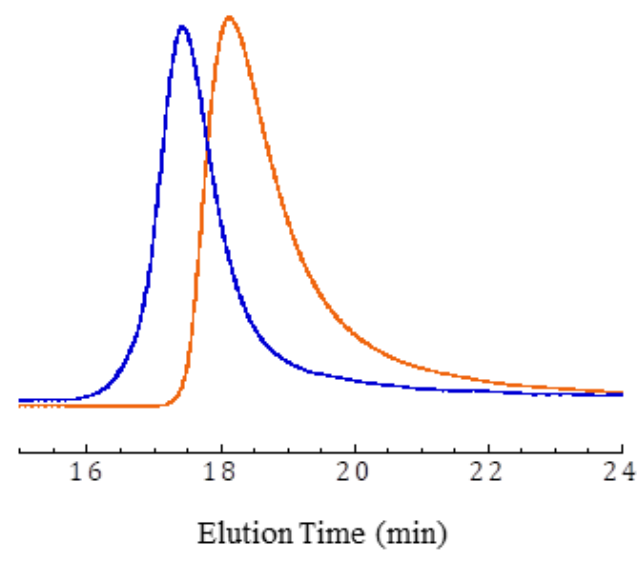

Figure 6. DMF GPC traces (refractive index detector) for the $\left.\mathrm{P}\left(\mathrm{GMA}_{65}-\text { stat-(MAm-GFF }\right)_{7}\right)$ macro-CTA (orange) and the diblock copolymer $\left.\mathrm{P}_{\left(\mathrm{GMA}_{65} \text {-stat-(MAm-GFF) }\right.}\right)$-b-PHPMA 28 (blue) prepared by RAFT aqueous dispersion polymerization of HPMA at $10 \% \mathrm{w} / \mathrm{w}$ at $70{ }^{\circ} \mathrm{C}$.

To investigate the morphology of the $\left.\mathrm{P}\left(\mathrm{GMA}_{65} \text {-stat-(MAm-GFF) }\right)_{7}\right)-b$-PHPMA 28 aggregates, TEM analysis was performed on diluted (100-fold) samples. Figure 7 shows that fibrous structures were obtained and that these fibers $(80-100 \mathrm{~nm})$ tended to arrange into sharp spherulitic structures. These structures are distinct but related to those observed for the $\left.\mathrm{P}\left(\mathrm{GMA}_{65}-\text { stat-(MAm-GFF }\right)_{7}\right)$ macro-CTA (Figure 4). However they are completely different from those resulting from the PISA of PGMA- $b$-PHPMA. ${ }^{12}$ This clearly underlines the influence of the GFF interactions on the self-assembly process. 

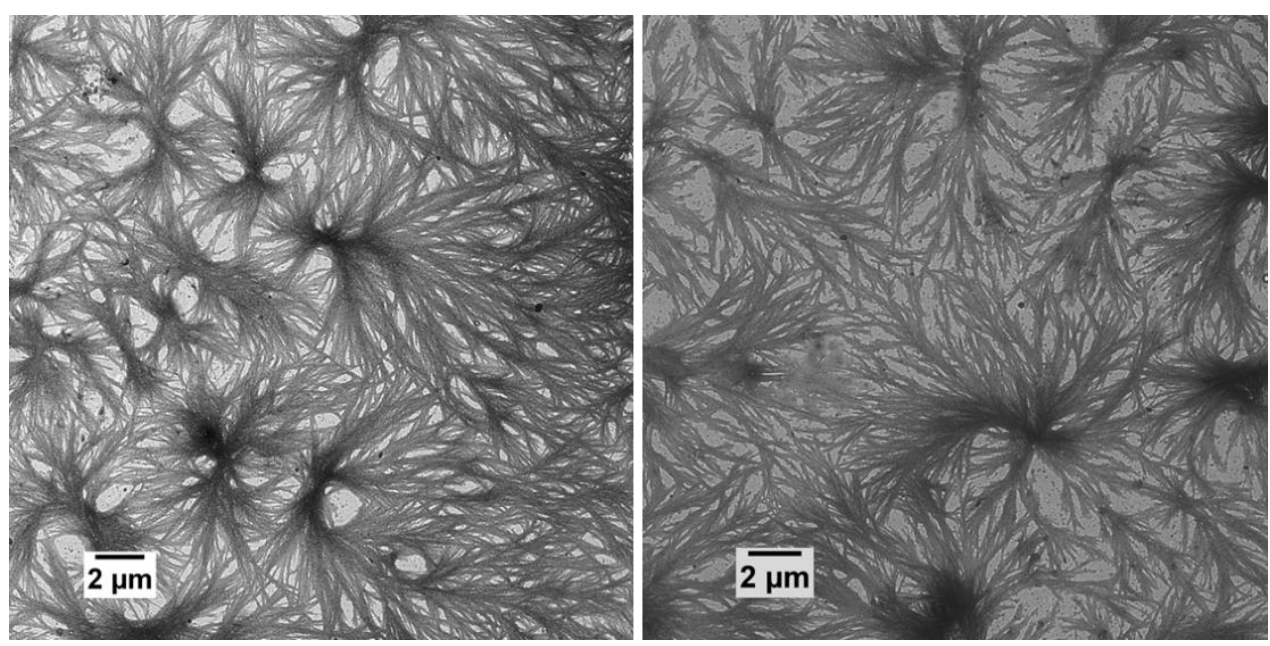

Figure 7. Representative TEM images of the $\mathrm{P}\left(\mathrm{GMA}_{65}\right.$-stat-(MAM-GFF) $\left.{ }_{7}\right)-b-\mathrm{PHPMA}_{28}$ diblock copolymer morphologies obtained by aqueous dispersion PISA and diluted to $0.1 \% \mathrm{w} / \mathrm{w}$ at ambient temperature.

To eliminate possible structural changes due to drying and sometimes observed in the case of postmortem TEM imaging, cryo-TEM and scattering techniques were used to provide further structural information. Figure $\mathbf{8}$ shows a cryo TEM image of the PISA morphologies obtained from the P(GMA $65^{-}$ stat-(MAm-GFF) $\left.{ }_{7}\right)-b$-PHPMA 28 diblock copolymer in water: 1-2 $\mu \mathrm{m}$ long and 50-100 nm wide fiberlike objects. These images demonstrate that these fibers are formed during polymerization and are not artefacts due to sample preparation and drying. The bundles visible in the non-cryogenic TEM, however, are absent from the cryo-TEM images and thus likely result from the drying process during post-mortem TEM grid preparation. 

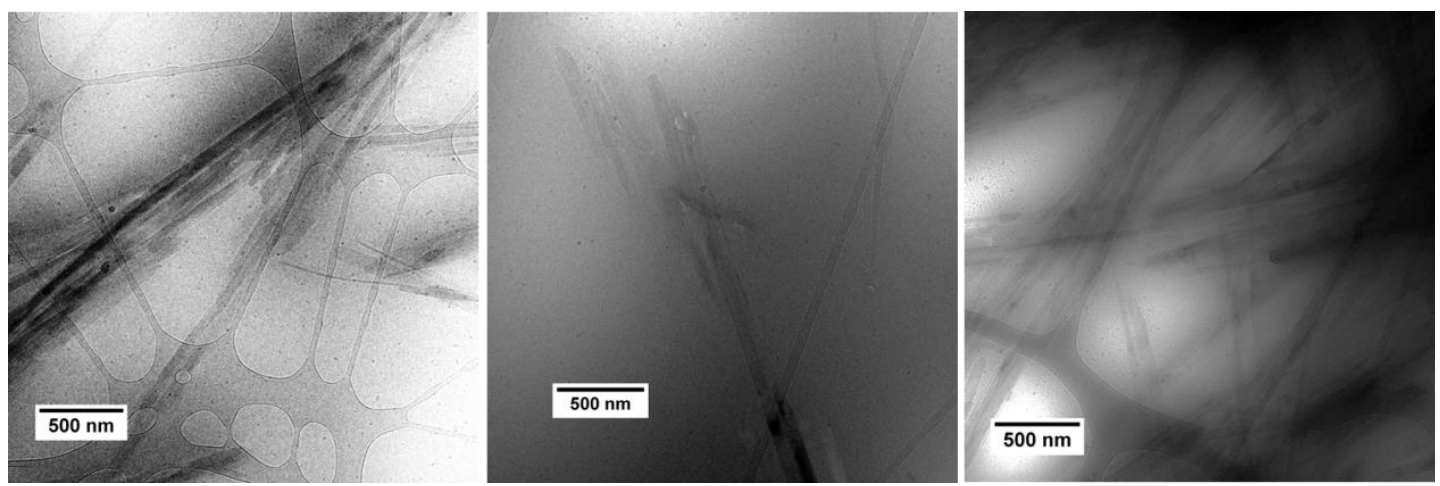

Figure 8. Representative cryo-TEM images of $\left.\mathrm{P}\left(\mathrm{GMA}_{65}-\text { stat-(MAm-GFF) }\right)_{7}\right)-b-\mathrm{PHPMA}_{28}$ diblock copolymers morphologies obtained from aqueous dispersion PISA at $10 \% \mathrm{w} / \mathrm{w}$.

Traditional DLS analyses where particles are assumed to be spherical are not adequate to examine such anisotropic structures. Hence, simultaneous polarized and depolarized $\left(90^{\circ}\right)$ DLS measurements were performed. In these experiments, two diffusion coefficients are determined: the translational coefficient $\left(D_{t}\right)$ and the rotational coefficient $\left(D_{r}\right)$, thus giving the length $(L)$ and also the width $(W)$ of the objects. The detail of the data analysis procedure can be found in supporting information (Figure S5- S7). The average width $(\mathrm{w}=250 \mathrm{~nm})$ and the approximate length $(200 \mathrm{~nm}<\mathrm{L}<1 \mu \mathrm{m})$ are in agreement with the cryo-TEM images. To further confirm the existence of the fibrous structures in solution, scattering techniques were used. SLS measurement in the q-range $0.005-0.035 \mathrm{~nm}^{-1}$ was combined with SAXS measurement over the q range $0.005-2 \mathrm{~nm}^{-1}$, providing the plot shown in Figure 9. A plateau of intensity is not obtained at low q, reflecting the presence of large object in the solution compared to the observation window. This plot displays $\mathrm{q}^{-2}$ scaling law at low q between $0.005 \mathrm{~nm}^{-1}$ and $0.035 \mathrm{~nm}^{-1}$ and $^{-1.5}$ scaling law at intermediate (or high) $\mathrm{q}$ (between $\mathrm{q} \sim 0.05 \mathrm{~nm}^{-1}$ and $\mathrm{q} \sim 0.2 \mathrm{~nm}^{-1}$. This scaling is close to what is expected for elongated structures $\left(\mathrm{q}^{-1}\right)$. The power law at high $\mathrm{q}$ suggests that the interfaces are not smooth. The bump at intermediate $\mathrm{q}\left(\mathrm{q} \sim 0.22 \mathrm{~nm}^{-1}\right)$ reveals a characteristic distance $(28 \mathrm{~nm})$ that most probably corresponds to the mean thickness of the ribbon/fiber. These results are consistent with 
the morphology observed in Cryo-TEM. However, the dimensions of the self-assembled objects could not be determined from these SLS and SAXS data because they are much larger than the upper size limit of $100 \mathrm{~nm}$.

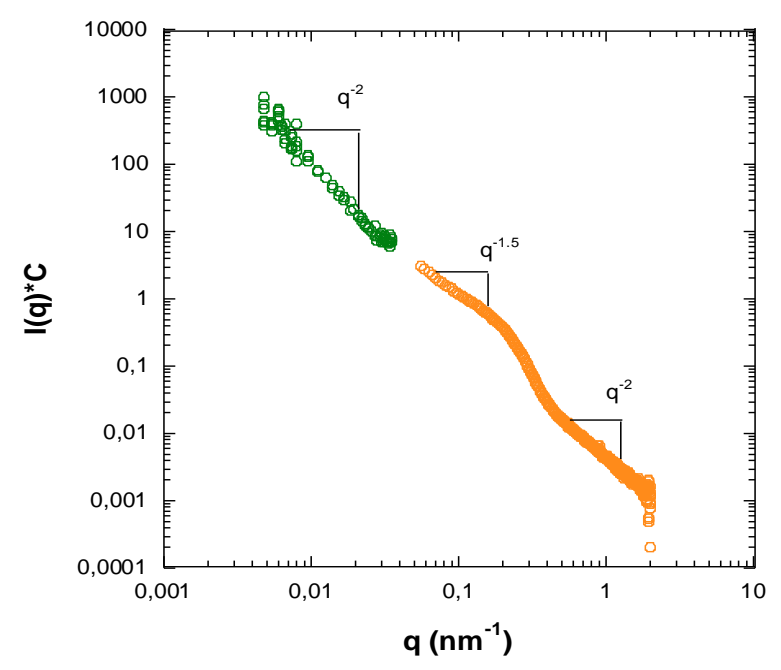

Figure 9. Combined SLS and SAXS plot obtained at $20^{\circ} \mathrm{C}$ for PISA suspension of P(GMA 65 -stat(MAm-GFF) 7 )- $b$-PHPMA 28 diblock copolymer. The I(q) values of the y-axis were multiplied by the suitable coefficients $(\mathrm{C})$ according to the dilution factors for running samples.

To explain the formation of these block copolymer structures, we surmise that the P(GMA65-stat$\left.(\mathrm{MAm}-\mathrm{GFF})_{7}\right)$ macro-CTA aggregates at $70^{\circ} \mathrm{C}$ (the temperature of the PISA protocol here), act as an exogeneous interface for heterogeneous nucleation for the self-assembly of the diblock copolymer. Indeed, the $\left.\mathrm{P}\left(\mathrm{GMA}_{65} \text {-stat-(MAm-GFF) }\right)_{7}\right)$ - $b$-PHPMA 28 diblock copolymer fibrous morphologies prepared via PISA and described above have never been reported for PGMA-b-PHPMA block copolymers. A PGMA $_{65}-b$-PHPMA 28 block copolymer would probably not self-assemble and if it did, would only lead to small spheres. ${ }^{11,74,75}$ These results strongly suggests that: 1) the peculiar structures observed here are directly caused by the GFF sequences in the macro-CTA, 2) the effect of the SAP is very strong even in 
polymers containing an average of only seven GFF moieties per molecule, and 3) the GFF sequences are accessible and remain active during the PISA process.

\section{Temperature-induced morphological changes}

A remarkable temperature-induced morphological change of the fiber-like structures formed from the $\left.\mathrm{P}\left(\mathrm{GMA}_{65} \text {-stat-(MAm-GFF) }\right)_{7}\right)-b$-PHPMA 28 block copolymer was detected by both DLS and TEM analysis. As seen in Figure 10, upon heating from $20{ }^{\circ} \mathrm{C}$ to $70{ }^{\circ} \mathrm{C}$, the bimodal distribution centered at $2 \mu \mathrm{m}$ and $40-50 \mathrm{~nm}$ of the self-assembled objects was significantly modified: the peak at $2 \mu \mathrm{m}$ decreased in intensity and shifted to $200 \mathrm{~nm}$ while the smaller size distribution increased in intensity. It is important to note that these changes were completely reversible as the DLS measurements carried out at $20^{\circ} \mathrm{C}$ before and after heating to $70^{\circ} \mathrm{C}$ were almost identical (Figure 10). TEM samples were prepared at $70^{\circ} \mathrm{C}$ from colloïdally stable solutions incubated at $70^{\circ} \mathrm{C}$ for at least 1 hour. These TEM images revealed worm-like structures of roughly $25 \mathrm{~nm}$ in diameter (Figure 10) instead of the flower-like fiber bundles seen at $20^{\circ} \mathrm{C}$ (Figure 7). Heating not only increase the mobility of the chains but is also known to weaken or even destroy hydrogen-bonds and $\pi-\pi$ stacking. ${ }^{48,76-78}$ While both interactions between GFF moieties and between GFF and water were significantly reduced at high temperature, the self-assembly of $\left.\mathrm{P}\left(\mathrm{GMA}_{65} \text {-stat-(MAm-GFF) }\right)_{7}\right)-b$-PHPMA 28 is mainly influenced by the PHPMA block which leads to this morphological transition. PGMA- $b$-PHPMA block copolymer particles exhibit thermo-responsive behavior with reversible morphology transition from worms to spheres upon cooling to $4{ }^{\circ} \mathrm{C} .{ }^{79}$ Thus, the effect of low temperature on the GFF-containing block copolymer was also studied. After incubation for $1 \mathrm{~h}$ at $4{ }^{\circ} \mathrm{C}$, another clear morphological change of the self-assembled structures was observed (Figure 11). The pure fiber phase was replaced by large spherical objects (ca. $600 \mathrm{~nm}$ in diameter) featuring a nanostructure composed of small spheres of roughly $25 \mathrm{~nm}$. These spherical clusters were reminiscent of Mimosa. The hydrophilicity increase of the PHPMA core-forming block at low temperature ${ }^{59,} 79-82$ likely triggered the reorganization of the $\left.\mathrm{P}\left(\mathrm{GMA}_{65} \text {-stat-(MAm-GFF }\right)_{7}\right)-b-\mathrm{PHPMA}_{28}$ self-assembled 
morphologies, suggesting that the self-assembly process of the GFF-containing block copolymer is not only driven by the specific peptide interaction part but also by the delicate hydrophilic/hydrophobic balance for the whole system.
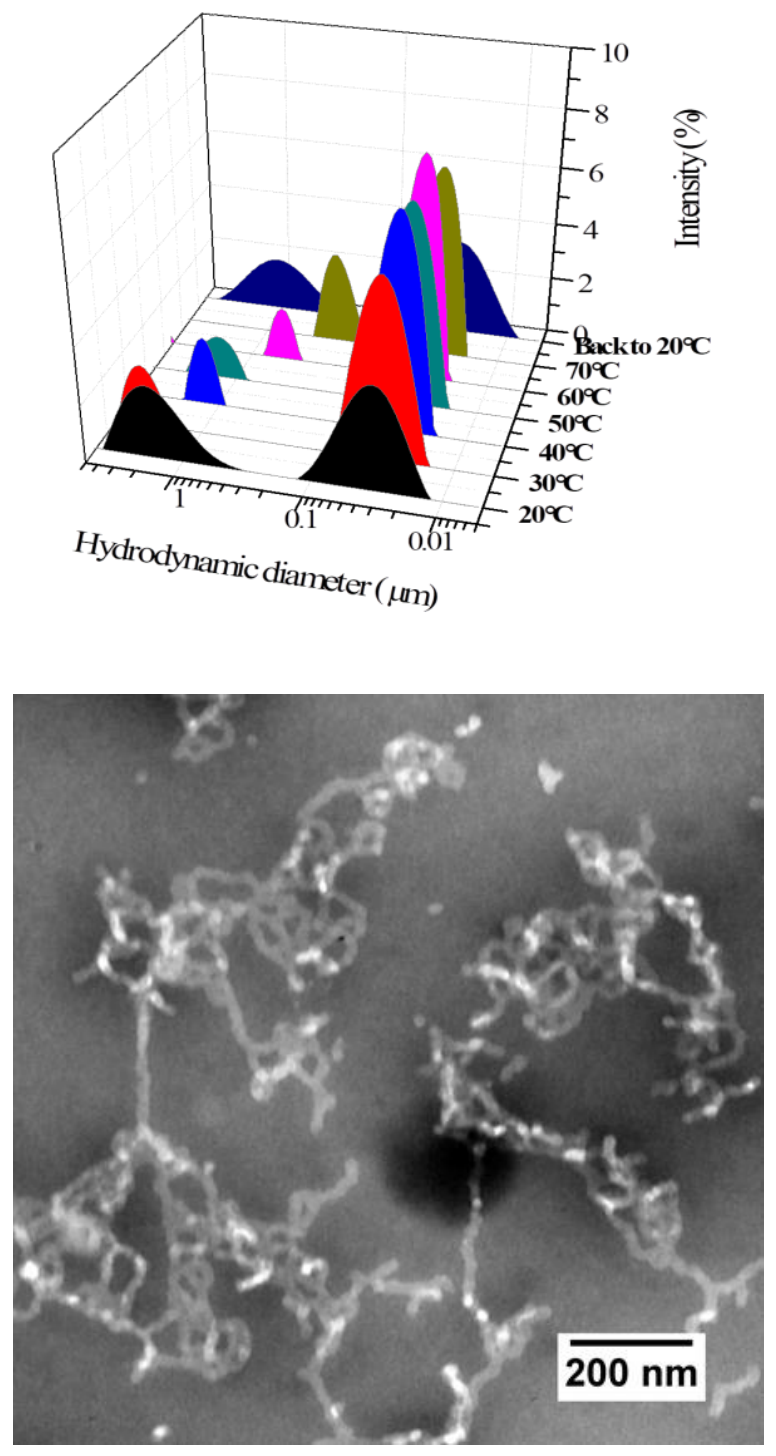

Figure 10. Evolution with temperature of the hydrodynamic diameter of $\mathrm{P}\left(\mathrm{GMA}_{65}-\right.$-stat-(MAm-GFF $\left.{ }_{7}\right)$ $b$-PHPMA 28 diblock copolymer objects at $0.1 \% \mathrm{w} / \mathrm{w}$ in MilliQ water (top) and representative TEM images of $\left.\mathrm{P}\left(\mathrm{GMA}_{65}-\text { stat-(MAm-GFF }\right)_{7}\right)-b-\mathrm{PHPMA}_{28}$ block copolymer structures at $0.1 \% \mathrm{w} / \mathrm{w}$ in MilliQ water incubated at $70^{\circ} \mathrm{C}$ for $1 \mathrm{~h}$ (bottom). 


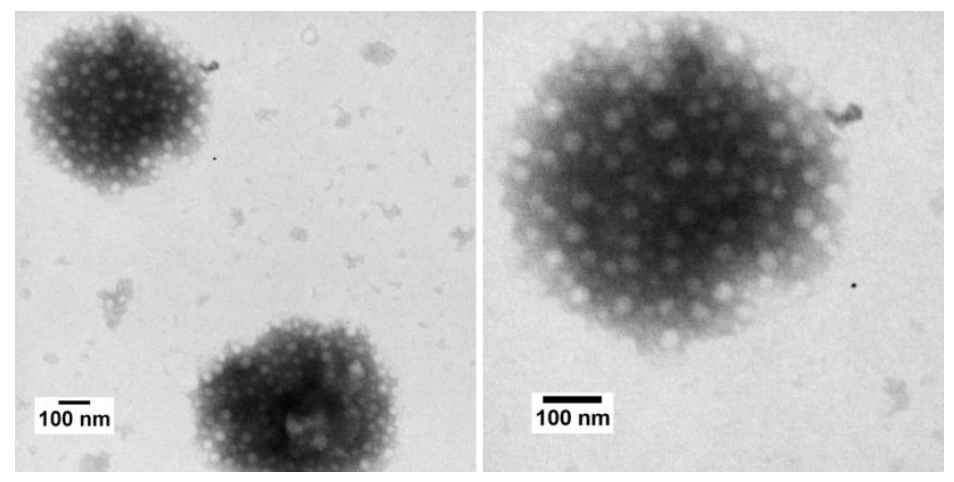

Figure 11. Representative TEM images $\left.\mathrm{P}\left(\mathrm{GMA}_{65} \text {-stat-(MAm-GFF) }\right)_{7}\right)-b$-PHPMA 28 block copolymer structures at $0.1 \% \mathrm{w} / \mathrm{w}$ in MilliQ water incubated at $4^{\circ} \mathrm{C}$ for $1 \mathrm{~h}$.

\section{CONCLUSIONS}

RAFT aqueous dispersion polymerization protocols using GFF self-assembling peptide (SAP) were used to prepare novel nano-objects. The influence of SAP on the resulting PISA morphologies was examined. The resulting $\left.\mathrm{P}\left(\mathrm{GMA}_{65} \text {-stat-(MAm-GFF) }\right)_{7}\right)-b-\mathrm{PHPMA}_{28}$ diblock copolymer formed selfassembled structures at $10 \% \mathrm{w} / \mathrm{w}$ which remained colloidally stable over six months. These structures and their evolution upon heating or cooling were examined using a combination of scattering techniques and electron microscopy. At $70^{\circ} \mathrm{C}$, the highly anisotropic fibers with $1-2 \mu \mathrm{m}$ long and $50-100 \mathrm{~nm}$ wide observed at $20^{\circ} \mathrm{C}$ were replaced by worm-like micelles. This morphological transition was fully reversible and is probably due to local rearrangement of the peptide moieties. The thermo-sensitive properties at lower temperature of PHPMA were also observed for this $\left.\mathrm{P}\left(\mathrm{GMA}_{65} \text {-stat-(MAm-GFF }\right)_{7}\right)-b$-PHPMA 28 diblock copolymer morphology. After incubation at $4{ }^{\circ} \mathrm{C}$, the rod-like structures turned into nanostructured spherical objects. This work demonstrates for the first time that the incorporation of SAP in a synthetic polymer strongly influences the shape and size of PISA-generated structures. One particularly salient point is that only seven GFF moieties per chain is sufficient to drastically change the selfassembly behavior of a diblock copolymer. This study highlights the essential role of the peptide inter- 
actions in the final morphologies. Given the structural diversity of polypeptides, this paves the way for the design of a wide range of self-assembled objects that might find application as asymmetric drug delivery systems ${ }^{45-47}$ or original scaffolds for tissue engineering for example.

\section{ASSOCIATED CONTENT}

\section{Supporting Information}

NMR spectra, HPLC profile, DDLS results.

\section{AUTHOR INFORMATION}

\section{Corresponding Author}

Mona Semsarillar - Institut Européen des Membranes, IEM, Univ Montpellier, CNRS, ENSCM, Montpellier, France, email: mona.semsarillar@umontpellier.fr

\section{Present addresses}

Thi Phuong Tuyen DAO - UPMC, Sorbonne Universités, Laboratoire PHENIX Physico-chimie des Electrolytes et Nanosystèmes Interfaciaux, CNRS, Paris, France

Email: thi-phuong-tuyen.dao@sorbonne-universite.fr

\section{Funding Sources}

PDRA fellowship managed by the French national research agency (ANR): "investissement d'Avenir" LabEX CheMISyst, grant number ANR-10-LABX-05-01. The authors also thank CNRS for funding this work via the "Osez l'interdisciplinarité" programme awarded to MS. F. Aubrit thanks M-Era.net program of Europe and the New Aquitaine Region (2017 call, FMF project) for postdoc fellowship.

\section{REFERENCES}

1. Penfold, N. J. W.; Yeow, J.; Boyer, C.; Armes, S. P., Emerging Trends in PolymerizationInduced Self-Assembly. ACS Macro Letters 2019, 8, 1029-1054.

2. D'Agosto, F.; Rieger, J.; Lansalot, M., RAFT-mediated polymerization-induced self-assembly. Angewandte Chemie International Edition 2020, 59, 8368-8392. 
3. Guégain, E.; Zhu, C.; Giovanardi, E.; Nicolas, J., Radical Ring-Opening CopolymerizationInduced Self-Assembly (rROPISA). Macromolecules 2019, 52, 3612-3624.

4. Ratcliffe, L. P. D.; Ryan, A. J.; Armes, S. P., From a Water-Immiscible Monomer to Block Copolymer Nano-Objects via a One-Pot RAFT Aqueous Dispersion Polymerization Formulation. Macromolecules 2013, 46, 769-777.

5. Varlas, S.; Foster, J. C.; O'Reilly, R. K., Ring-opening metathesis polymerization-induced selfassembly (ROMPISA). Chemical Communications 2019, 55, 9066-9071.

6. Wang, J.; Wu, Z.; Wang, G.; Matyjaszewski, K., In Situ Crosslinking of Nanoparticles in Polymerization-Induced Self-Assembly via ARGET ATRP of Glycidyl Methacrylate. Macromolecular Rapid Communications 2019, 40, 1800332.

7. Darabi, A.; Jessop, P. G.; Cunningham, M. F., One-Pot Synthesis of Poly((diethylamino)ethyl methacrylate-co-styrene)-b-poly(methyl methacrylate-co-styrene) Nanoparticles via Nitroxide-Mediated Polymerization. Macromolecules 2015, 48, 1952-1958.

8. $\quad$ Ferguson, C. J.; Hughes, R. J.; Pham, B. T. T.; Hawkett, B. S.; Gilbert, R. G.; Serelis, A. K.; Such, C. H., Effective ab Initio Emulsion Polymerization under RAFT Control. Macromolecules 2002, 35, 9243-9245.

9. Lansalot, M.; Rieger, J., Polymerization-Induced Self-Assembly. Macromolecular Rapid Communications 2019, 40, 1800885.

10. Semsarilar, M.; Ladmiral, V.; Blanazs, A.; Armes, S. P., Anionic Polyelectrolyte-Stabilized Nanoparticles via RAFT Aqueous Dispersion Polymerization. Langmuir 2012, 28, 914-922.

11. Blanazs, A.; Madsen, J.; Battaglia, G.; Ryan, A. J.; Armes, S. P., Mechanistic Insights for Block Copolymer Morphologies: How Do Worms Form Vesicles? Journal of the American Chemical Society 2011, 133, 16581-16587.

12. Blanazs, A.; Ryan, A. J.; Armes, S. P., Predictive Phase Diagrams for RAFT Aqueous Dispersion Polymerization: Effect of Block Copolymer Composition, Molecular Weight, and Copolymer Concentration. Macromolecules 2012, 45, 5099-5107.

13. Chambon, P.; Blanazs, A.; Battaglia, G.; Armes, S. P., Facile Synthesis of Methacrylic ABC Triblock Copolymer Vesicles by RAFT Aqueous Dispersion Polymerization. Macromolecules 2012, 45, 5081-5090.

14. Semsarilar, M.; Ladmiral, V.; Blanazs, A.; Armes, S. P., Cationic Polyelectrolyte-Stabilized Nanoparticles via RAFT Aqueous Dispersion Polymerization. Langmuir 2013, 29, 7416-7424. 15. Boissé, S.; Rieger, J.; Khaled, B.; Di-Cicco, A.; Beaunier, P.; Li, M.-H.; Charleux, B., Amphiphilic block copolymer nano-fibers via RAFT-mediated polymerization in aqueous dispersed system. Chemical communications 2010, 46, 1950-1952.

16. Chaduc, I.; Crepet, A.; Boyron, O.; Charleux, B.; D’Agosto, F.; Lansalot, M., Effect of the pH on the RAFT Polymerization of Acrylic Acid in Water. Application to the Synthesis of Poly(acrylic acid)-Stabilized Polystyrene Particles by RAFT Emulsion Polymerization. Macromolecules 2013, 46, 6013-6023.

17. Zhang, W.; D’Agosto, F.; Boyron, O.; Rieger, J.; Charleux, B., One-Pot Synthesis of Poly(methacrylic acid-co-poly(ethylene oxide) methyl ether methacrylate)-b-polystyrene Amphiphilic Block Copolymers and Their Self-Assemblies in Water via RAFT-Mediated Radical Emulsion Polymerization. A Kinetic Study. Macromolecules 2011, 44, 7584-7593.

18. Chaduc, I.; Zhang, W.; Rieger, J.; Lansalot, M.; D'Agosto, F.; Charleux, B., Amphiphilic Block Copolymers from a Direct and One-pot RAFT Synthesis in Water. Macromolecular rapid communications 2011, 32, 1270-1276.

19. Derry, M.; Fielding, L.; Armes, S., Polymerization-Induced Self-Assembly of Block Copolymer Nanoparticles via RAFT Non-Aqueous Dispersion Polymerization. Progress in Polymer Science 2015, $52,1-18$. 
20. Semsarilar, M.; Jones, L.; Blanazs, A.; Armes, S., Efficient Synthesis of Sterically-Stabilized Nano-Objects via RAFT Dispersion Polymerization of Benzyl Methacrylate in Alcoholic Media. Advanced materials 2012, 24, 3378-3382.

21. Jones, E. R.; Semsarilar, M.; Blanazs, A.; Armes, S. P., Efficient Synthesis of AmineFunctional Diblock Copolymer Nanoparticles via RAFT Dispersion Polymerization of Benzyl Methacrylate in Alcoholic Media. Macromolecules 2012, 45, 5091-5098.

22. Semsarilar, M.; Ladmiral, V.; Blanazs, A.; Armes, S., Poly(methacrylic acid)-based AB and ABC block copolymer nano-objects prepared via RAFT alcoholic dispersion polymerization. Polym. Chem. 2014, 5, 3466-3475.

23. Semsarilar, M.; Penfold, N.; Jones, L.; Armes, S., Semi-Crystalline Diblock Copolymer NanoObjects Prepared via RAFT Alcoholic Dispersion Polymerization of Stearyl Methacrylate. Polym. Chem. 2015, 6, 1751-1757.

24. Zhao, W.; Gody, G.; Dong, S.; Zetterlund, P.; Perrier, S., Optimisation of the RAFT Polymerization Conditions for the in Situ Formation of Nano-objects via Dispersion Polymerization in Alcoholic Medium. Polym. Chem. 2014, 5, 6990-7003.

25. Zhang, X.; Rieger, J.; Charleux, B., Effect of the solvent composition on the morphology of nano-objects synthesized via RAFT polymerization of benzyl methacrylate in dispersed systems. Polym. Chem. 2012, 3, 1502-1509.

26. Fielding, L.; Derry, M.; Ladmiral, V.; Rosselgong, J.; Malho Rodrigues, A.; Ratcliffe, L.; Sugihara, S.; Armes, S., RAFT dispersion polymerization in non-polar solvents: Facile production of block copolymer spheres, worms and vesicles in n-alkanes. Chem. Sci. 2013, 4, 2081-2087.

27. Derry, M.; Fielding, L.; Armes, S., Industrially-Relevant Polymerization-Induced SelfAssembly Formulations in Non-Polar Solvents: RAFT Dispersion Polymerization of Benzyl Methacrylate. Polym. Chem. 2015, 6, 3054-3062.

28. Fielding, L.; Lane, J.; Derry, M.; Mykhaylyk, O.; Armes, S., Thermo-responsive Diblock Copolymer Worm Gels in Non-Polar Solvents. Journal of the American Chemical Society 2014, 136, 5790-5798.

29. Lopez-Oliva, A.; Warren, N.; Rajkumar, A.; Mykhaylyk, O.; Derry, M.; Doncom, K.; Rymaruk, M.; Armes, S., Polydimethylsiloxane-Based Diblock Copolymer Nano-objects Prepared in Nonpolar Media via RAFT-Mediated Polymerization-Induced Self-Assembly. Macromolecules 2015, 48, 3547-3555.

30. Zhang, Q.; Zhu, S., Ionic Liquids: Versatile Media for Preparation of Vesicles from Polymerization-Induced Self-Assembly. ACS Macro Letters 2015, 4, 755-758.

31. Zhou, D.; Kuchel, R. P.; Dong, S.; Lucien, F. P.; Perrier, S.; Zetterlund, P. B., PolymerizationInduced Self-Assembly under Compressed $\mathrm{CO}_{2}$ : Control of Morphology Using a $\mathrm{CO}_{2}$-Responsive MacroRAFT Agent. Macromolecular Rapid Communications 2019, 40, 1800335.

32. Dong, S.; Zhao, W.; Lucien, F.; Perrier, S.; Zetterlund, P., Polymerization induced selfassembly: Tuning of nano-object morphology by use of $\mathrm{CO}_{2}$. Polym. Chem. 2015, 6, 2249-2254. 33. Xu, A.; Lu, Q.; Huo, Z.; Ma, J.; Geng, B.; Azhar, U.; Zhang, L.; Zhang, S., Synthesis of fluorinated nanoparticles: Via RAFT dispersion polymerization-induced self-assembly using fluorinated macro-RAFT agents in supercritical carbon dioxide. RSC Advances 2017, 7, 51612-51620.

34. Warren, N. J.; Armes, S. P., Polymerization-Induced Self-Assembly of Block Copolymer Nanoobjects via RAFT Aqueous Dispersion Polymerization. Journal of the American Chemical Society 2014, 136, 10174-10185.

35. Sugihara, S.; Blanazs, A.; Armes, S. P.; Ryan, A. J.; Lewis, A. L., Aqueous Dispersion Polymerization: A New Paradigm for in Situ Block Copolymer Self-Assembly in Concentrated Solution. Journal of the American Chemical Society 2011, 133, 15707-15713. 
36. Zhang, X.; Boissé, S.; Zhang, W.; Beaunier, P.; D’Agosto, F.; Rieger, J.; Charleux, B., WellDefined Amphiphilic Block Copolymers and Nano-objects Formed in Situ via RAFT-Mediated Aqueous Emulsion Polymerization. Macromolecules 2011, 44, 4149-4158.

37. He, W.-D.; Sun, X.-L.; Wan, W.-M.; Pan, C.-Y., Multiple Morphologies of PAA-b-PSt Assemblies throughout RAFT Dispersion Polymerization of Styrene with PAA Macro-CTA.

Macromolecules 2011, 44, 3358-3365.

38. Le, D.; Keller, D.; Delaittre, G., Reactive and Functional Nanoobject(s) by PolymerizationInduced Self-Assembly. Macromolecular Rapid Communications 2018, 40, 1800551.

39. Cobo, I.; Li, M.; Sumerlin, B.; Perrier, S., Smart hybrid materials by conjugation of responsive polymers to biomacromolecules. Nature materials 2015, 14, 143-159.

40. Sumerlin, B., Proteins as Initiators of Controlled Radical Polymerization: Grafting- from via ATRP and RAFT. ACS Macro Letters 2012, 1, 141-145.

41. Li, H.; Li, M.; Yu, X.; Bapat, A.; Sumerlin, B., Block copolymer conjugates prepared by sequentially grafting from proteins via RAFT. Polymer Chemistry 2011, 2, 1531-1535.

42. Vanparijs, N.; Maji, S.; Louage, B.; Voorhaar, L.; Laplace, D.; Zhang, Q.; Shi, Y.; Hennink, W.; Richard, H.; De Geest, B., Polymer-protein conjugation via a 'grafting to' approach - A comparative study of the performance of protein-reactive RAFT chain transfer agents. Polym. Chem. 2015, 6, 5602-5614.

43. Ayres, L.; Vos, M.; Adams, P.; Shklyarevskiy, I.; Hest, J., Elastin-Based Side-Chain Polymers Synthesized by ATRP. Macromolecules 2003, 36, 5967-5973.

44. Luppi, L.; Babut, T.; Petit, E.; Rolland, M.; Quémener, D.; Soussan, L.; Semsarilar, M.; Moradi, M.-A., Antimicrobial Polylysine Decorated Nano-Structures Prepared through Polymerization Induced Self-Assembly (PISA). Polym. Chem. 2019, 10, 336-344.

45. Habibi, N.; Kamaly, N.; Memic, A.; Shafiee, H., Self-assembled peptide-based nanostructures: Smart nanomaterials toward targeted drug delivery. Nano Today 2016, 11, 41-60.

46. Webber, M. J.; Appel, E. A.; Meijer, E. W.; Langer, R., Supramolecular biomaterials. Nature Materials 2016, 15, 13-26.

47. Spicer, C.; Jumeaux, C.; Gupta, B.; M. Stevens, M., Peptide and protein nanoparticle conjugates: Versatile platforms for biomedical applications. Chemical Society Reviews 2018, 47, 35743620 .

48. Wang, J.; Liu, K.; Xing, R.; Yan, X., Peptide self-assembly: Thermodynamics and kinetics. Chemical Society reviews 2016, 45, 5589-5604.

49. Marchesan, S.; Vargiu, A.; Styan, K., The Phe-Phe Motif for Peptide Self-Assembly in Nanomedicine. Molecules 2015, 20, 19775-19788.

50. Gazit, E., Reductionist Approach in Peptide-Based Nanotechnology. Annual Review of Biochemistry 2018, 87, 533-553.

51. Reches, M.; Gazit, E., Reches, M. \& Gazit, E. Controlled patterning of aligned self-assembled peptide nanotubes. Nat. Nanotechnol. 1, 195-200. Nature nanotechnology 2006, 1, 195-200.

52. Han, T. H.; Kim, J.; Park, J. S.; Park, C.; Ihee, H.; Kim, S., Liquid Crystalline Peptide Nanowires. Advanced Materials 2007, 19, 3924-3927.

53. Yan, X.; He, Q.; Wang, K.; Duan, L.; Cui, Y.; Li, J., Transition of Cationic Dipeptide Nanotubes into Vesicles and Oligonucleotide Delivery. Angewandte Chemie 2007, 46, 2431-2434.

54. Smith, A.; Williams, R.; Tang, C.; Coppo, P.; Collins, R.; Turner, m.; Saiani, A.; Ulijn, R., Fmoc-Diphenylalanine Self Assembles to a Hydrogel via a Novel Architecture Based on $\pi-\pi$ Interlocked $\beta$-Sheets. Advanced Materials 2008, 20, 37-41.

55. Görbitz, C., The Structure of Nanotubes Formed by Diphenylalanine, The Core Recognition Motif of Alzheimer's Beta-Amyloid Polypeptide. Chemical communications 2006, 22, 2332-2334. 
56. Guo, C.; Luo, Y.; Zhou, R.; Wei, G., Probing the Self-Assembly Mechanism of

Diphenylalanine-Based Peptide Nanovesicles and Nanotubes. ACS Nano 2012, 6, 3907-3918.

57. Adler-Abramovich, L.; Reches, M.; Sedman, V. L.; Allen, S.; Tendler, S. J. B.; Gazit, E., Thermal and Chemical Stability of Diphenylalanine Peptide Nanotubes: Implications for Nanotechnological Applications. Langmuir 2006, 22, 1313-1320.

58. Lovett, J. R.; Warren, N. J.; Armes, S. P.; Smallridge, M. J.; Cracknell, R. B., Order-Order Morphological Transitions for Dual Stimulus Responsive Diblock Copolymer Vesicles.

Macromolecules 2016, 49, 1016-1025.

59. Warren, N. J.; Derry, M. J.; Mykhaylyk, O. O.; Lovett, J. R.; Ratcliffe, L. P. D.; Ladmiral, V.; Blanazs, A.; Fielding, L. A.; Armes, S. P., Critical Dependence of Molecular Weight on

Thermoresponsive Behavior of Diblock Copolymer Worm Gels in Aqueous Solution. Macromolecules 2018, 51, 8357-8371.

60. Verber, R.; Blanazs, A.; Armes, S., Rheological studies of thermo-responsive diblock copolymer worm gels. Soft Matter 2012, 8, 9915-9922.

61. Deng, R.; Ning, Y.; Jones, L.; Cunningham, V.; Penfold, N.; Armes, S., Stimulus-responsive Block Copolymer Nano-Objects and Hydrogels via Dynamic Covalent Chemistry. Polym. Chem. 2017, 8, 5374-5380.

62. $\quad$ Deng, R.; Derry, M.; Mable, C.; Ning, Y.; Armes, S., Using Dynamic Covalent Chemistry To Drive Morphological Transitions: Controlled Release of Encapsulated Nanoparticles from Block Copolymer Vesicles. Journal of the American Chemical Society 2017, 139, 7616-7623.

63. C. Chan, W.; White, P. D., Fmoc Solid-Phase Peptide Synthesis: A Practical Approach. Oxford University Press: New York: 2000; Vol. 222.

64. Eimer, W.; Pecora, R., Rotational and translational diffusion of short rodlike molecules in solution: Oligonucleotides. The Journal of Chemical Physics 1991, 94, 2324-2329.

65. Singh, V.; Snigdha, K.; Singh, C.; Sinha, N.; Thakur, A., Understanding the self-assembly of Fmoc-phenylalanine to hydrogel formation. Soft Matter 2015, 11, 5353-5364.

66. Li, Q.; Jia, Y.; Dai, L.; Li, J., Controlled Rod Nanostructured Assembly of Diphenylalanine and Their Optical Waveguide Properties. ACS nano 2015, 9, 2689-2695.

67. Görbitz, C., Nanotube Formation by Hydrophobic Dipeptides. Chemistry 2002, 7, 5153-5159.

68. Huang, R.; Qi, W.; Su, R.; Zhao, J.; He, Z., Solvent and surface controlled self-assembly of

diphenylalanine peptide: From microtubes to nanofibers. Soft Matter 2011, 7, 6418-6421.

69. Tomar, D.; Chaudhary, S.; Jena, K. C., Self-assembly of 1-phenylalanine amino acid:

electrostatic induced hindrance of fibril formation. RSC advances 2019, 9, 12596-12605.

70. Hatton, F.; Lovett, J.; Armes, S., Synthesis of well-defined epoxy-functional spherical nanoparticles by RAFT aqueous emulsion polymerization. Polym. Chem. 2017, 8, 4856-4868.

71. Canning, S. L.; Smith, G. N.; Armes, S. P., A Critical Appraisal of RAFT-Mediated Polymerization-Induced Self-Assembly. Macromolecules 2016, 49, 1985-2001.

72. Cunningham, V.; Alswieleh, A.; Thompson, K.; Williams, M.; Leggett, G.; Armes, S.; Musa, O., Poly(glycerol monomethacrylate)-Poly(benzyl methacrylate) Diblock Copolymer Nanoparticles via RAFT Emulsion Polymerization: Synthesis, Characterization, and Interfacial Activity. Macromolecules 2014, 47, 5613-5623.

73. Ladmiral, V.; Semsarilar, M.; Canton, I.; Armes, S. P., Polymerization-Induced Self-Assembly of Galactose-Functionalized Biocompatible Diblock Copolymers for Intracellular Delivery. Journal of the American Chemical Society 2013, 135 (36), 13574-13581.

74. Mable, C. J.; Thompson, K. L.; Derry, M. J.; Mykhaylyk, O. O.; Binks, B. P.; Armes, S. P., ABC Triblock Copolymer Worms: Synthesis, Characterization, and Evaluation as Pickering Emulsifiers for Millimeter-Sized Droplets. Macromolecules 2016, 49, 7897-7907. 
75. Li, Y.; Armes, S., RAFT Synthesis of Sterically Stabilized Methacrylic Nanolatexes and Vesicles by Aqueous Dispersion Polymerization. 2010, 49, 4042-4046.

76. Huang, R.; Wang, Y.; Qi, W.; Su, R.; He, Z., Temperature-induced reversible self-assembly of diphenylalanine peptide and the structural transition from organogel to crystalline nanowires. Nanoscale research letters 2014, 9, 653.

77. Kim, J.; Han, T. H.; Kim, Y.-I.; Park, J. S.; Choi, J.; Churchill, D.; Kim, S.; Ihee, H., Role of Water in Directing Diphenylalanine Assembly into Nanotubes and Nanowires. Advanced materials 2010, 22, 583-587.

78. Yang, D.; Gao, S.; Fang, Y.; Lin, X.; Jin, X.; Wang, X.; Ke, L.; Shi, K., The $\pi-\pi$ stackingguided supramolecular self-assembly of nanomedicine for effective delivery of antineoplastic therapies. Nanomedicine 2018, 13 (24), 3159-3177.

79. $\quad$ Blanazs, A.; Verber, R.; Mykhaylyk, O. O.; Ryan, A. J.; Heath, J. Z.; Douglas, C. W. I.; Armes, S. P., Sterilizable Gels from Thermoresponsive Block Copolymer Worms. Journal of the American Chemical Society 2012, 134, 9741-9748.

80. Ratcliffe, L.; Derry, M.; Ianiro, A.; Tuinier, R.; Armes, S., A Single Thermoresponsive Diblock Copolymer Can Form Spheres, Worms or Vesicles in Aqueous Solution. Angewandte Chemie International Edition 2019, 58, 18964-18970.

81. North, S. M.; Armes, S. P., Aqueous solution behavior of stimulus-responsive poly(methacrylic acid)-poly(2-hydroxypropyl methacrylate) diblock copolymer nanoparticles. Polymer Chemistry 2020, $11,2147-2156$.

82. Penfold, N. J. W.; Whatley, J. R.; Armes, S. P., Thermoreversible Block Copolymer Worm Gels Using Binary Mixtures of PEG Stabilizer Blocks. Macromolecules 2019, 52, 1653-1662. 